\title{
The photorespiratory hydrogen shuttle
}

\section{Synthesis of phthalonic acid and its use in the characterization of the malate/aspartate shuttle in pea (Pisum sativum) leaf mitochondria}

\author{
Ian B. DRY, ${ }^{*}$ Eugene DIMITRIADIS, $\dagger$ A. David WARD $\dagger$ and Joseph T. WISKICH* \\ Departments of *Botany and †Organic Chemistry, University of Adelaide, Adelaide, S.A. 5001, Australia
}

\begin{abstract}
A method is presented for the preparation of pure phthalonic acid (PTA) in high yields. This PTA was used to determine the capacity of the malate/aspartate shuttle in pea (Pisum sativum) leaf mitochondria. The inhibition of glycine-dependent $\mathrm{O}_{2}$ uptake in the combined presence of $5 \mathrm{~mm}$-aspartate and $5 \mathrm{~mm}$ 2-oxoglutarate (2-OG) was decreased by $55 \pm 22 \%(n=13)$ in washed and $50 \pm 2 \%(n=11)$ in purified mitochondria by 0.23 mM-PTA. This concentration of PTA had no effect on the oxidation of $5 \mathrm{~mm}-2-\mathrm{OG}$, suggesting that part of the observed inhibition of $\mathrm{O}_{2}$ uptake in the presence of aspartate and 2-OG was due to the production of oxaloacetate (OAA) by aspartate aminotransferase external to the mitochondrial inner membrane. Levels of external aspartate aminotransferase were estimated to be $24 \pm 1 \%(n=4)$ and $13 \pm 1 \%(n=4)$ of the total mitochondrial activity in washed and purified mitochondria respectively. Malate/aspartate-shuttle activity was estimated directly by measuring rates of malate efflux from isolated mitochondria and was found to match estimates of shuttle activity based on the PTA-insensitive inhibition of $\mathrm{O}_{2}$ uptake. Comparisons of malate/aspartate- and malate/OAA-shuttle activities indicated potentially similar rates of NADH export from pea leaf mitochondria under conditions in vivo. These extrapolated to whole-tissue rates of $5-11 \mu \mathrm{mol}$ of $\mathrm{NADH} \cdot \mathrm{h}^{-1} \cdot \mathrm{mg}$ of chlorophyll ${ }^{-1}$. The potential role of the malate/aspartate shuttle in the support of photorespiratory glycine oxidation in leaf tissue is discussed.
\end{abstract}

\section{INTRODUCTION}

One of the major questions yet to be resolved regarding the operation of the photorespiratory cycle is the fate of the NADH generated during the oxidation of glycine within leaf mitochondria (for reviews, see Gardestrom \& Edwards, 1985; Dry et al., 1987). Glycine oxidation via glycine decarboxylase may be linked to the mitochondrial respiratory chain (Douce et al., 1977; Moore et al., 1977; Day \& Wiskich, 1981). Furthermore, it may occur 'preferentially' at the expense of tricarboxylic-acid-cycle substrates in a competitive situation in which the potential supply of reducing equivalents from the mitochondrial dehydrogenases exceeds the oxidative capacity of the respiratory chain (Day \& Wiskich, 1981; Bergman \& Ericson, 1983; Dry et al., 1983). Even so, maximal rates of glycine oxidation via the respiratory chain alone (in vivo) may not be sufficient to account for the estimated rates of photorespiratory flux in photosynthetic tissues (Dry \& Wiskich, 1987), particularly if, as suggested by some, the activity of the mitochondrial respiratory chain, in photosynthetic tissue, is restricted in the light (Chevallier \& Douce, 1976; Canvin et al., 1980; Graham, 1980).

Alternatively, it has been proposed that the NADH generated during glycine oxidation may be reoxidized either via a malate/OAA (Woo \& Osmond, 1976; Ebbighausen et al., 1985) or a malate/aspartate shuttle (Journet et al., 1981) which may be linked in vivo to hydroxypyruvate reduction in the peroxisomes. On the basis of rates of OAA uptake into isolated leaf mitochondria, Ebbighausen et al. (1985) predicted that malate/OAA-shuttle activities could account for the reoxidation of all of the NADH produced during photorespiratory glycine oxidation in vivo. In contrast, Day \& Wiskich (1981), using malate efflux as a measure of shuttle capacity, suggested that rates of NADH reoxidation via the malate/OAA shuttle were, at best, only half that obtained with the respiratory chain (under State-3 conditions) and thus could not account for rates of glycine oxidation in vivo.

There is significantly less information available regarding the capacity of the malate/aspartate shuttle in leaf tissue. This shuttle has been shown to support rates of malate decarboxylation, via 'malic' enzyme in crassulacean-acid-metabolism leaf mitochondria, at rates approaching those of State-3 conditions (Day, 1980). In the leaf mitochondria of plants exhibiting ' $\mathrm{C}_{3}$ ' metabolism, however, estimates of shuttle activity are based solely on measurements of the degree of inhibition of glycine-dependent $\mathrm{O}_{2}$ uptake by isolated leaf mitochondria in the presence of aspartate and 2-OG (Journet et al., 1981). No attempt has been made to assess the shuttle capacity in terms of malate efflux from the mitochondrion nor quantify the shuttle rates on a whole-tissue basis. The present paper re-examines the operation of the malate/aspartate shuttle in pea (Pisum sativum) leaf mitochondria in an attempt to determine its potential role in the export of reducing equivalents from the mitochondria under photorespiratory conditions.

Much of the work in the present study has involved the use of the mitochondrial transport inhibitor phthalonic acid (PTA; Meijer et al., 1976; Day \& Wiskich, 1981). PTA is not commercially available; hence this material needs to be prepared in the laboratory. It is important,

\footnotetext{
Abbreviations used: 2-OG, 2-oxoglutarate; AsAT, aspartate aminotransferase; BSA, bovine serum albumin; OAA, oxaloacetate; PTA, phthalonic acid (phthalonate); PVP, polyvinylpyrrolidone.
} 
therefore, to have available a reproducible procedure that provides a product of known purity in reasonable yield. The procedures for the preparation of PTA, as described in the literature (von Braun, 1923; Gardner \& Naylor, 1943; Fieser \& Fieser, 1967), are insufficiently detailed, and unless considerable care is exercised, normally produces poor yields of an impure product. We describe a method which results in a high yield of pure PTA with no detectable impurities.

\section{EXPERIMENTAL}

\section{Plant material}

Pea (Pisum sativum L., cv. Massey Gem) seedlings were grown in trays of Vermiculite or soil in a glasshouse for 12-15 days.

\section{Chemicals}

PTA (about $92 \%$ pure) was prepared as follows. Into a 3-litre three-necked flask fitted with an efficient mechanical stirrer, a reflux condenser and a dropping funnel were placed $500 \mathrm{ml}$ of $0.5 \mathrm{M}-\mathrm{NaOH}$ and $32 \mathrm{~g}$ of naphthalene. The contents of the flask were heated just to boiling point and stirred while a hot solution of $\mathrm{KMnO}_{4}(212 \mathrm{~g})$ in water $(1500 \mathrm{ml})$ was added over a $1-1.5 \mathrm{~h}$ period. Vigorous stirring was necessary during the addition, but little or no heating was necessary to maintain the mixture at the boiling point. During this time any sublimed naphthalene was pushed back into the flask from the condenser with a glass rod. At the conclusion of the addition of the $\mathrm{KMnO}_{4}$ the solution was heated at reflux for 30-60 min. During this time the colour of the permanganate ions was discharged. The cooled solution was then filtered through a pad of Celite and concentrated in a large evaporating dish or beaker on a hotplate to approx. 100-150 $\mathrm{ml}$. The concentrated solution was then acidified with $30 \%(\mathrm{v} / \mathrm{v}) \mathrm{H}_{2} \mathrm{SO}_{4}$ to pH 3.5 (considerable effervescence occurs). The solid that precipitates on cooling consists mainly of inorganic salts with some phthalic acid. The filtered solution was continuously extracted with diethyl ether for 2 days; the diethyl ether extracts were dried (with anhydrous $\mathrm{MgSO}_{4}$ ) and evaporated to dryness to yield a viscous oil which solidified on standing. The crude phthalonic acid $(22 \mathrm{~g})$ was then dissolved in diethyl ether $(5-6 \mathrm{ml} / \mathrm{g})$ and insoluble phthalic acid removed by filtration. The PTA usually can be crystallized by addition of hexane (or light petroleum, b.p. $60-80^{\circ} \mathrm{C}$ ) to the filtrate. This isolated PTA $(19.5 \mathrm{~g})$ has m.p. $142-145^{\circ} \mathrm{C}$ and a purity of approx. $92 \%$, the remainder being accounted for mainly by phthalic acid (as determined by g.l.c. of the derived methyl esters and by ${ }^{13} \mathrm{C}$-n.m.r. spectroscopy of the isolated material).

Pure PTA was prepared by dissolving crude PTA $(5.0 \mathrm{~g}, 92 \%$ pure $)$ in diethyl ether $(20 \mathrm{ml})$ and a slight excess of a solution of diazomethane in diethyl ether added to the cooled (ice bath) solution. Excess of diazomethane is indicated by the appearance of a pale yellow colour in the reaction solution or can be tested for by the evolution of gas when a glass rod dipped in acetic acid is inserted into the solution. The excess of diazomethane and some of the diethyl ether was removed under vacuum until the remaining volume was about $10 \mathrm{ml}$. Cooling the solution at $-10^{\circ} \mathrm{C}$ for some days gave colourless prisms $(4.0 \mathrm{~g})$ of the dimethyl ester, m.p. $64-65^{\circ} \mathrm{C}$ (literature m.p. $66-68^{\circ} \mathrm{C}$; Wegschieder $\&$
Glogau, 1903), which could be obtained by filtration and washing of the crystals with a little cold diethyl ether. Dimethyl PTA $(3.0 \mathrm{~g})$ was dissolved in $20 \mathrm{ml}$ of dry methanol, a solution of $\mathrm{KOH}(2.0 \mathrm{~g})$ in dry methanol $(30 \mathrm{ml})$ was added and the solution was left at room temperature for $4 \mathrm{~h}$. Colourless platelets of the potassium salt form rapidly. The mixture was filtered, and the solid was washed with a little cold methanol and with diethyl ether to yield the pure dipotassium salt $(3.7 \mathrm{~g})$. Dipotassium PTA $(2.7 \mathrm{~g})$ was suspended in diethyl ether $(60 \mathrm{ml})$ and $\mathrm{HCl}(2.5 \mathrm{ml}, 10 \mathrm{mM})$ was added. The solution was stirred vigorously for $20 \mathrm{~min}$, then $5.0 \mathrm{~g}$ of anhydrous $\mathrm{MgSO}_{4}$ was added and the solution was stirred vigorously for a further $15 \mathrm{~min}$. The mixture was filtered and the solids were washed thoroughly with diethyl ether $(3 \times 30 \mathrm{ml})$. Evaporation of the diethyl ether gave a colourless viscous oil which crystallized when kept under high vacuum to remove occluded diethyl ether; yield $1.9 \mathrm{~g}$, m.p. $147-148^{\circ} \mathrm{C}$ (literature m.p. $146^{\circ} \mathrm{C}$; Kuroda \& Perkin, 1923). There were no detectable impurities in the final product (as determined by g.l.c. of the derived methyl ester and by ${ }^{13}$ C-n.m.r. spectroscopy).

All other chemicals were obtained from either Sigma Chemical Co. or Boehringer Mannheim G.m.b.H.

\section{Mitochondrial isolation}

Pea leaves $(40 \mathrm{~g})$ were disrupted with a Polytron PTA-3S probe for $2-3 \mathrm{~s}$ in $200 \mathrm{ml}$ of ice-cold medium containing $0.3 \mathrm{~m}$-sorbitol, $50 \mathrm{~mm}$-Tes, $1 \mathrm{~mm}$-EDTA, $1 \mathrm{mM}-\mathrm{MgCl}_{2}, 10 \mathrm{~mm}$-isoascorbate, $1 \%$ (w/v) PVP-40 and $0.4 \%(\mathrm{w} / \mathrm{v}) \mathrm{BSA}$, all adjusted to $\mathrm{pH} 7.5$. The homogenate was filtered through two layers of Miracloth and centrifuged for $5 \mathrm{~min}$ at $2000 \mathrm{~g}$. The supernatant was centrifuged at $10000 \mathrm{~g}$ for $20 \mathrm{~min}$ and the pellet washed by resuspending in $60 \mathrm{ml}$ of $0.3 \mathrm{M}$-sorbitol containing $20 \mathrm{~mm}$-Tes, $\mathrm{pH} 7.5,0.1 \%$ (w/v) BSA and re-centrifuging at $10000 \mathrm{~g}$ for $20 \mathrm{~min}$. Final resuspension was in $2-3 \mathrm{ml}$ of wash medium. These were denoted 'washed' mitochondria. Purified mitochondria were obtained using either a Percoll/PVP gradient as described by Day et al. (1985) or using a discontinuous Percoll gradient consisting of four layers: $15,28,46$ and $60 \%(\mathrm{v} / \mathrm{v})$ Percoll containing $0.3 \mathrm{M}$-sucrose, $10 \mathrm{mM}-\mathrm{KH}_{2} \mathrm{PO}_{4}$ and $0.1 \%(\mathrm{w} / \mathrm{v}) \mathrm{BSA}, \mathrm{pH}$ 7.5. The gradient was centrifuged at $40000 \mathrm{~g}$ for $\mathbf{4 0} \mathrm{min}$ in a Beckman SW-28 swing-out rotor and the mitochondria collected from the $28 / 46 \%$ Percoll interface. These mitochondria were washed twice by diluting in wash medium and centrifuging at $10000 \mathrm{~g}$ for $20 \mathrm{~min}$.

\section{Assay procedures}

$\mathrm{O}_{2}$ consumption was measured polarographically in $2.0 \mathrm{ml}$ of standard reaction medium containing $0.3 \mathrm{M}$ sorbitol, $10 \mathrm{~mm}$-Tes, $10 \mathrm{~mm}-\mathrm{KH}_{2} \mathrm{PO}_{4}, 2 \mathrm{~mm}-\mathrm{MgCl}_{2}$ and $0.1 \%(\mathrm{w} / \mathrm{v}) \mathrm{BSA}$, all adjusted to pH 7.2, with a Rank oxygen electrode (Rank Brothers, Cambridge, U.K.) at $25^{\circ} \mathrm{C}$.

Aspartate aminotransferase was assayed spectrophotometrically by monitoring NADH oxidation in the presence of malate dehydrogenase at $340 \mathrm{~nm}$. Unless stated otherwise, the standard assay contained $2.5 \mathrm{ml}$ of standard reaction medium (see above), 4 units of malate dehydrogenase, $5 \mathrm{~mm}-2-\mathrm{OG}, 0.21 \mathrm{mM}-\mathrm{NADH}, 5 \mu \mathrm{M}$ antimycin A, $0.8 \mathrm{~mm}$-PTA, $10 \mathrm{~mm}$-glycine and approx. $0.2 \mathrm{mg}$ of mitochondrial protein. The reaction was initiated with $5 \mathrm{~mm}$-aspartate. 
(a)

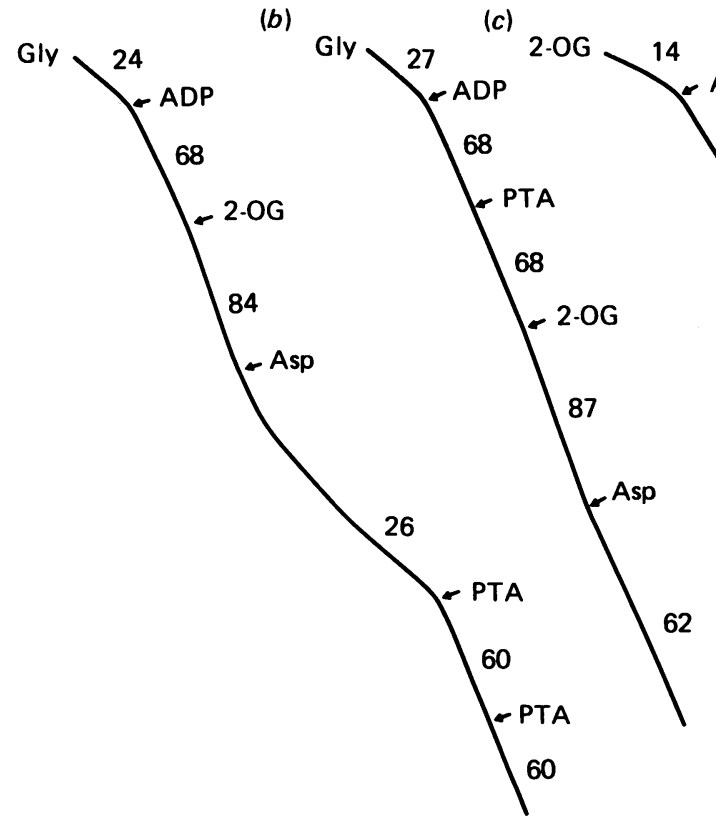

(d)

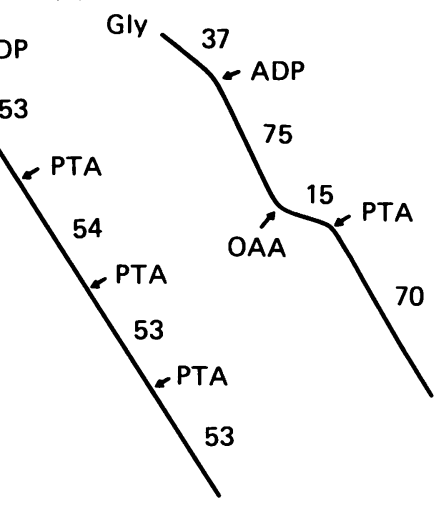

Fig. 1. Effect of PTA on some oxidative properties of washed pea leaf mitochondria

All assay mixtures contained $10 \mathrm{~mm}$-glycine (Gly), except (c), which contained $10 \mathrm{~mm}$-2-OG, 2 mM-malonate and $0.1 \mathrm{mM}$-thiamin pyrophosphate. Additions: $1 \mathrm{~mm}$-ADP, $5 \mathrm{~mm}$-2-OG, $5 \mathrm{~mm}$-aspartate (Asp), $0.23 \mathrm{~mm}$-PTA and $0.12 \mathrm{~mm}$-OAA. Assays $(a-c)$ and $(d)$ represent separate mitochondrial preparations. Rates are expressed as $\mathrm{nmol}$ of $\mathrm{O}_{2}$ consumed $\cdot \mathrm{min}^{-1} \cdot \mathrm{mg}$ of protein ${ }^{-1}$.

\section{Measurement of shuttle activity}

The rate of malate efflux from isolated mitochondria was measured spectrophotometrically by monitoring the reduction of NADP at $340 \mathrm{~nm}$ in the presence of chicken liver NADP-dependent 'malic' enzyme. 'Malic' enzyme, suspended in $\left(\mathrm{NH}_{4}\right)_{2} \mathrm{SO}_{4}$, was desalted before use on a Sephadex G-25 column (PD-10; Pharmacia Fine Chemicals) in $20 \mathrm{~mm}-\mathrm{Hepes} / \mathrm{KOH}, \mathrm{pH} 7.5$, containing $2 \mathrm{~mm}$ dithiothreitol. Purified mitochondria $(0.3-0.4 \mathrm{mg}$ of protein) were added to $1.0 \mathrm{ml}$ of standard reaction medium, which also contained 1 unit of NADPdependent 'malic' enzyme, 0.25 mM-PTA, 10 mM-glycine, 1 mM-EGTA and 0.1-0.2 mM-ADP, and incubated at $25^{\circ} \mathrm{C}$ for $2-3 \mathrm{~min}$. To this was added $4 \mathrm{~mm}$-NADP and $5 \mu \mathrm{M}$-antimycin A. Malate/aspartate-shuttle activity was initiated by the addition of $5 \mathrm{~mm}-2-\mathrm{OG}$, followed by $5 \mathrm{~mm}$-aspartate. Malate/OAA-shuttle activity was initiated by the addition of OAA.

\section{Protein and chlorophyll determination}

Protein was determined as described by Lowry $e t$ al. (1951), with BSA as a standard. Chlorophyll was determined by the method of Arnon (1949). Mitochondrial protein was corrected for the contribution by broken thylakoids by assuming a thylakoid protein/ chlorophyll ratio of 6.9:1 (Nash \& Wiskich, 1982).

\section{RESULTS}

\section{Inhibition of glycine-dependent $\mathrm{O}_{2}$ uptake by (aspartate + 2-OG)}

Fig. 1 shows the effect of the addition of 2-OG and aspartate to isolated pea leaf mitochondria oxidizing glycine. The rate of $\mathrm{O}_{2}$ uptake increased on the addition of 2-OG, but decreased markedly on the further addition of aspartate (Fig. 1a). Journet et al. (1981) have proposed that this inhibition of $\mathrm{O}_{2}$ uptake results from the uptake of aspartate and 2-OG into the mitochondria and the subsequent generation of OAA via intramitochondrial aspartate aminotransferase (AsAT). The OAA so produced then reoxidizes matrix NADH via a reversal of the malate dehydrogenase reaction, resulting in an inhibition of $\mathrm{O}_{2}$ uptake. The results of Fig. 1, however, show that this inhibition may be partially reversed by PTA, a specific inhibitor of OAA uptake into plant mitochondria (Moore et al., 1979; Day \& Wiskich, 1981). This suggests that part of the aspartate/2-OG-dependent inhibition of $\mathrm{O}_{2}$ uptake is due to the production of OAA by AsAT external to the inner membrane and its subsequent transport into the mitochondrial matrix. Fig. $1(d)$ demonstrates that the concentration of PTA used was sufficient to inhibit OAA transport into the mitochondria.

Similar results were also obtained with purified pea leaf mitochondria. The average contribution of externally generated OAA to the total inhibition of $\mathrm{O}_{2}$ uptake (based on the $\mathrm{O}_{2}$ uptake rate after 2-OG addition) was estimated at $55 \pm 2 \%(n=13)$ for washed mitochondria and $50 \pm 2 \%(n=11)$ for purified mitochondria.

\section{Effect of PTA on 2-OG oxidation}

PTA is a highly effective inhibitor of 2-OG transport in rat liver mitochondria (Meijer et al., 1976). Therefore, one possible explanation of the results of Fig. 1 may be that PTA reverses the aspartate/2-OG-dependent inhibition by inhibiting 2-OG uptake. However, conflicting reports have been produced regarding the effectiveness of PTA as an inhibitor of 2-OG transport into plant mitochondria (Day \& Wiskich, 1981; Proudlove \& Moore, 1984; Ebbighausen et al., 1985).

Fig. 2 illustrates the effect of PTA on 2-OG oxidation 


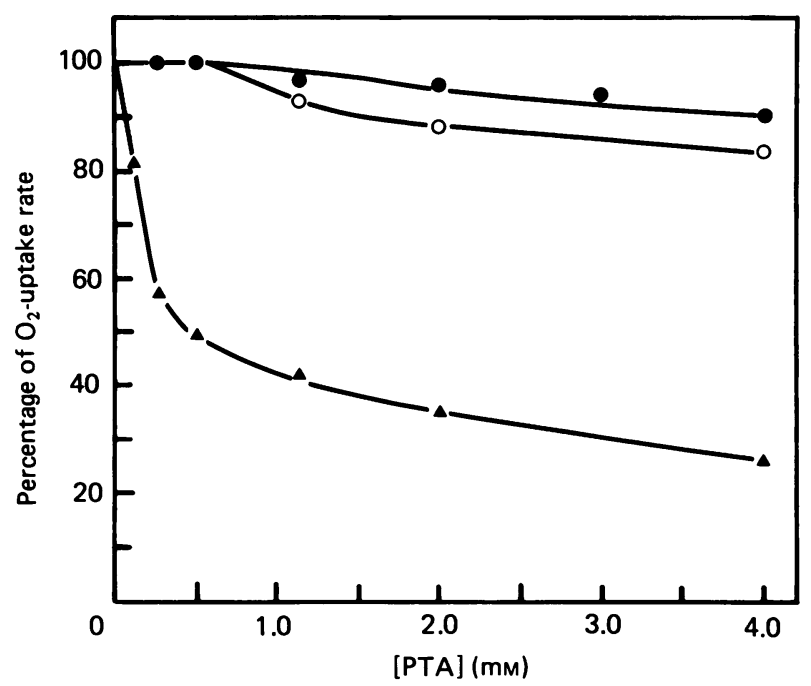

Fig. 2. Effect of PTA on 2-OG oxidation by washed pea leaf mitochondria

Standard assay contained $2 \mathrm{~mm}$-malonate, $0.1 \mathrm{~mm}$-thiamin pyrophosphate, $1.0 \mathrm{~mm}$-ADP and various concentrations of 2-OG. Each point represents a separate assay and is the mean for two separate experiments. Symbols: $10 \mathrm{~mm}$ 2-OG; O, $5 \mathrm{~mm}-2-\mathrm{OG}$; $\triangle, 1 \mathrm{~mm} 2-\mathrm{OG}$. Rates are expressed as a percentage of the uninhibited State-3 rate.

by washed pea leaf mitochondria. It can be seen that the degree of inhibition of 2-OG oxidation by PTA is a function of the 2-OG concentration. Thus 1 mM-PTA produced a $58 \%$ inhibition of $\mathrm{O}_{2}$ uptake at $1 \mathrm{~mm}-2-\mathrm{OG}$, but only a $1 \%$ inhibition at 10 mM-2-OG. Similarly, Ebbighausen et al. (1985) found no effect of $1 \mathrm{mM}-\mathrm{PTA}$ on the rate of $\mathrm{O}_{2}$ uptake by spinach leaf mitochondria oxidizing $10 \mathrm{~mm}-2-\mathrm{OG}$.

Fig. 1(c) also illustrates the effects of 0.23-0.7 mM-PTA on 2-OG oxidation at $5 \mathrm{~mm}-2-\mathrm{OG}$. If one assumes that all of the 2-OG utilized in the generation of OAA must enter the mitochondrion, then rates of 2-OG uptake via the shuttle (see Fig. 1a) would be similar to those observed during 2-OG oxidation (Fig. 1c). Thus the insensitivity of the 2-OG oxidation rate to the addition of 0.23 mM-PTA strongly suggests that the PTA reversal of the aspartate/2-OG-dependent inhibition cannot be explained by an inhibition of 2-OG uptake. Finally, it is (a)

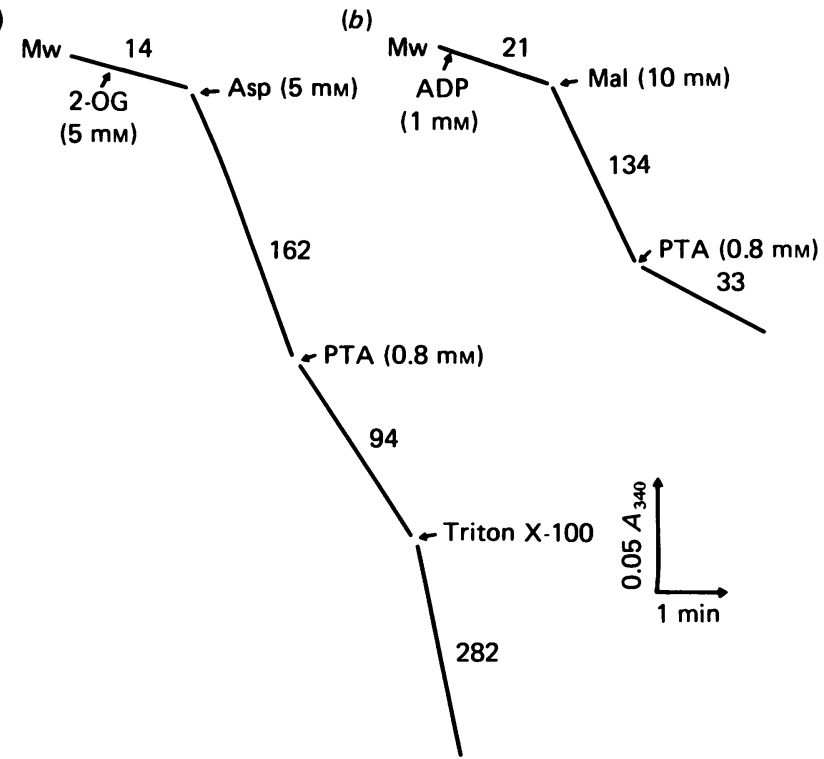

Fig. 3. Estimation of external AsAT activity associated with washed pea leaf mitochondria (Mw)

Assay mixtures contained $2.5 \mathrm{ml}$ of standard reaction medium, $2 \mathrm{~mm}-\mathrm{EGTA}, \quad 0.21 \mathrm{~mm}-\mathrm{NADH}, \quad 0.16 \mathrm{mg}$ of mitochondrial protein and 4 units of malate dehydrogenase. The assay mixture in $(a)$ also contained $5 \mu \mathrm{M}$-antimycin A. Triton X-100 was present at $0.05 \%(\mathrm{v} / \mathrm{v})$. Rates are expressed as $\mathrm{nmol}$ of $\mathrm{NADH}$ oxidized $\cdot \mathrm{min}^{-1} \cdot \mathrm{mg}$ of protein $^{-1}$. Abbreviations: Asp, aspartate; Mal, malate.

clear from Fig. 1(b) that the presence of PTA does not inhibit the stimulation of $\mathrm{O}_{2}$ uptake observed on the addition of 2-OG, again indicating that 0.23 mM-PTA does not appear to be restricting the rate of 2-OG uptake under these conditions.

\section{Estimation of external AsAT activity}

The effects of PTA shown in Fig. 1 suggest the presence of AsAT external to the inner membrane of these pea leaf mitochondrial preparations. This was verified by measuring OAA production by intact pea leaf mitochondria in the presence of aspartate and 2-OG. One potential source of error in this estimation results from the production of OAA by intramitochondrial

Table 1. Levels of external AsAT activity associated with pea leaf mitochondria

Assays performed as described in the Experimental section. Total activity was determined in the presence of $0.05 \%(\mathrm{v} / \mathrm{v}) \mathrm{Triton}$ $\mathrm{X}-100$. Results are averages for four separate mitochondrial preparations.

\begin{tabular}{lccc}
\hline & \multicolumn{3}{c}{ AsAT activity } \\
\cline { 2 - 3 } & $\begin{array}{c}\text { (nmol of NADH oxidized } \cdot \min ^{-1} \cdot \mathrm{mg} \\
\text { of protein }\end{array}$ \\
\cline { 2 - 3 } Preparation & $(a)$ Intact* $^{*}$ & $(b)+$ Detergent & $\begin{array}{r}\{\% \text { External } \\
[100 \times(a) /(b)]\}\end{array}$ \\
\hline Washed & $51 \pm 9$ & $210 \pm 31$ & $24 \pm 1$ \\
Purified & $34 \pm 3$ & $259 \pm 35$ & $13 \pm 1$
\end{tabular}

* Alternative estimates of external AsAT activity derived from the PTA-sensitive increase in $\mathrm{O}_{2}$ uptake (as in Fig. 1): washed, $54 \mathrm{nmol}$ of NADH oxidized $\cdot \mathrm{min}^{-1} \cdot \mathrm{mg}$ of protein ${ }^{-1}$; purified, $50 \mathrm{nmol}$ of NADH oxidized $\cdot \mathrm{min}^{-1} \cdot \mathrm{mg} \mathrm{of}^{\mathrm{N}} \mathrm{protein}^{-1}$. 


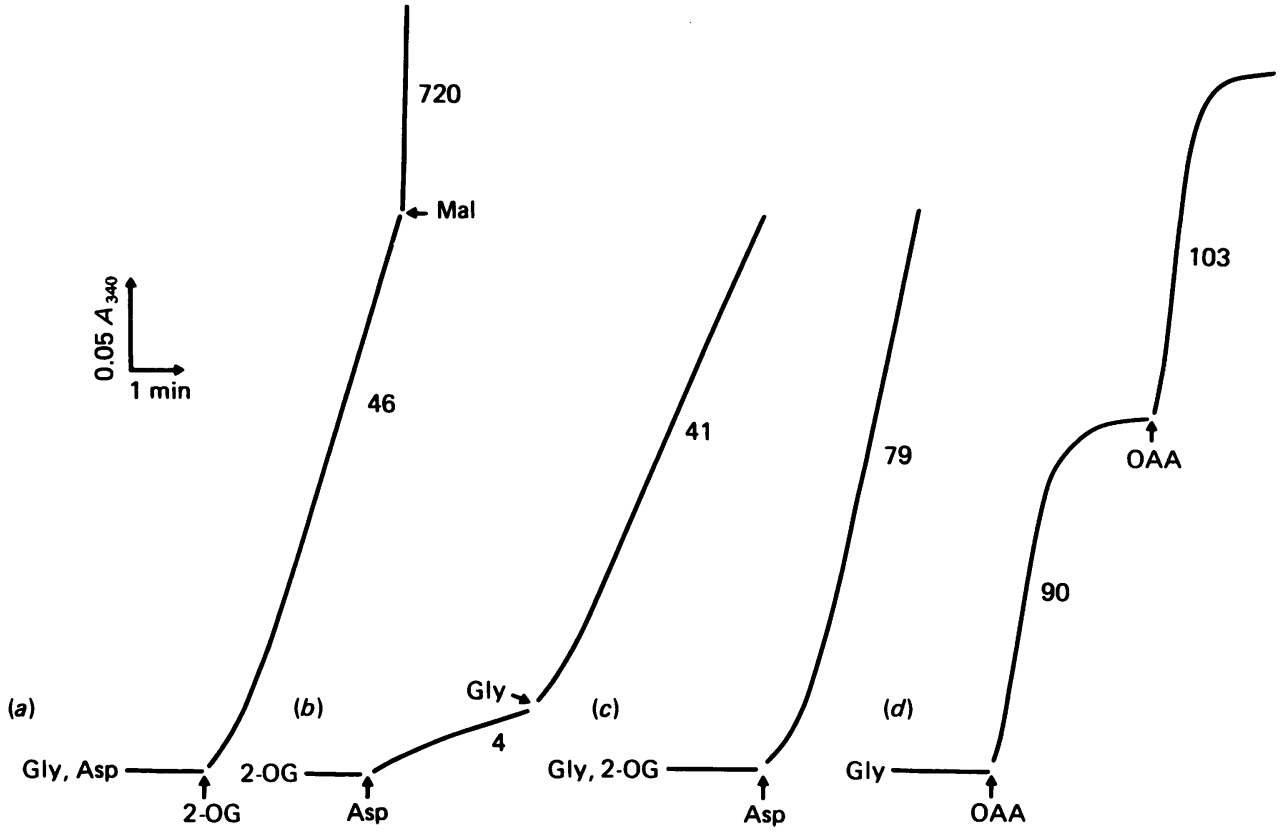

Fig. 4. Estimation of malate/aspartate- and malate/OAA-shuttle activities via malate effiux from purified pea leaf mitochondria

Assays were performed essentially as described in the Experimental section, with the following exceptions: (b), no glycine; $(c)$, no PTA. Additions: $5 \mathrm{~mm}-2-\mathrm{OG}, 10 \mathrm{~mm}$-glycine, $0.1 \mathrm{~mm}$-malate and $30 \mu \mathrm{M}$-OAA. Rates are expressed as nmol of NADPH produced $\cdot \min ^{-1} \cdot \mathrm{mg}$ of protein ${ }^{-1}$. Abbreviations: Asp, aspartate; Gly, glycine; Mal, malate.

AsAT and its subsequent export into the external compartment, leading to an overestimation of external AsAT activity. Fig. 3(a) illustrates the decrease in measurable 'external' AsAT activity observed on addition of 0.8 mM-PTA. This concentration of PTA had no effect on total AsAT activity in vitro (results not shown), but was found to almost completely inhibit export of OAA from mitochondria incubated with malate under State-3 conditions (Fig. 3b). Glycine was subsequently included in all assays to decrease intramitochondrial OAA (via malate dehydrogenase) and further minimize the potential contribution of internal AsAT activity to the measurable external activity. Total external activities measured under these conditions are shown in Table 1. Similar results were obtained with mitochondria purified on a PVP/Percoll or a discontinuous Percoll gradient (see the Experimental section) and thus these results have been pooled. The levels of external AsAT activity measured by using this method were found to be consistently lower, but within the range of activities estimated from the observed increase in $\mathrm{O}_{2}$ uptake on addition of PTA (see Table 1).

These results confirm the existence of AsAT external to the inner membrane of pea leaf mitochondria and support the hypothesis that PTA addition results in a partial reversal of aspartate/2-OG-dependent inhibition of $\mathrm{O}_{2}$ uptake, because of the contribution of externally generated OAA to the total inhibition

\section{Estimation of malate/aspartate-shuttle activity via malate effiux}

The results above clearly indicate that estimates of malate/aspartate-shuttle activities based on inhibitions of $\mathrm{O}_{2}$ uptake are only valid if carried out in the presence of PTA. Such estimates, however, are based only on the rates of uptake of aspartate and 2-OG and supply no information as to the rate of export of shuttle intermediates, such as malate, from the mitochondrion.

Malate efflux from purified pea leaf mitochondria in the presence of aspartate and 2-OG was measured by monitoring the reduction of extramitochondrial NADP in the presence of NADP-dependent 'malic' enzyme. External NADPH oxidation was inhibited by the presence of $1 \mathrm{~mm}$-EGTA (Nash \& Wiskich, 1983). External NADP reduction was found to be dependent on the presence of aspartate, 2-OG and substrate, i.e. glycine, for the generation of intramitochondrial NADH (Figs. $4 a$ and $4 b$ ). The small background rate observed in the absence of glycine (Fig. $4 b$ ) was due to the generation of NADH by 2-OG oxidation. The addition of a small quantity of malate dramatically increased the rate of NADP reduction, demonstrating that malate efflux was limiting the rate of 'malic'-enzyme activity and thus extramitochondrial NADP reduction. Rates of malate efflux were markedly increased in the absence of PTA (Fig. 4c), owing to the contribution of external AsAT to the generation of OAA and, subsequently, malate. Shuttle activity was also found to be maximized by preincubation of mitochondria with glycine and ADP as used in the oxygen-electrode studies (see Fig. 1). This also allowed for a more direct comparison between shuttle activities measured using malate efflux and those based on PTA-insensitive inhibitions of glycine-dependent $\mathrm{O}_{2}$ consumption (Fig. 1). On average, estimates of shuttle activity based on malate efflux were $47 \pm 5(n=5)$ $\mathrm{nmol}$ of NADH oxidized $\cdot \mathrm{min}^{-1} \cdot \mathrm{mg}$ of protein ${ }^{-1} \mathrm{com}$ pared with the $\mathrm{O}_{2}$ uptake estimates of $62 \pm 2(n=5) \mathrm{nmol}$ of NADH oxidized $\cdot \mathrm{min}^{-1} \cdot \mathrm{mg}$ of protein $^{-1}$. Thus there appears to be reasonable agreement between the estimated rates of malate/aspartate-shuttle activity when these two methods are used. 


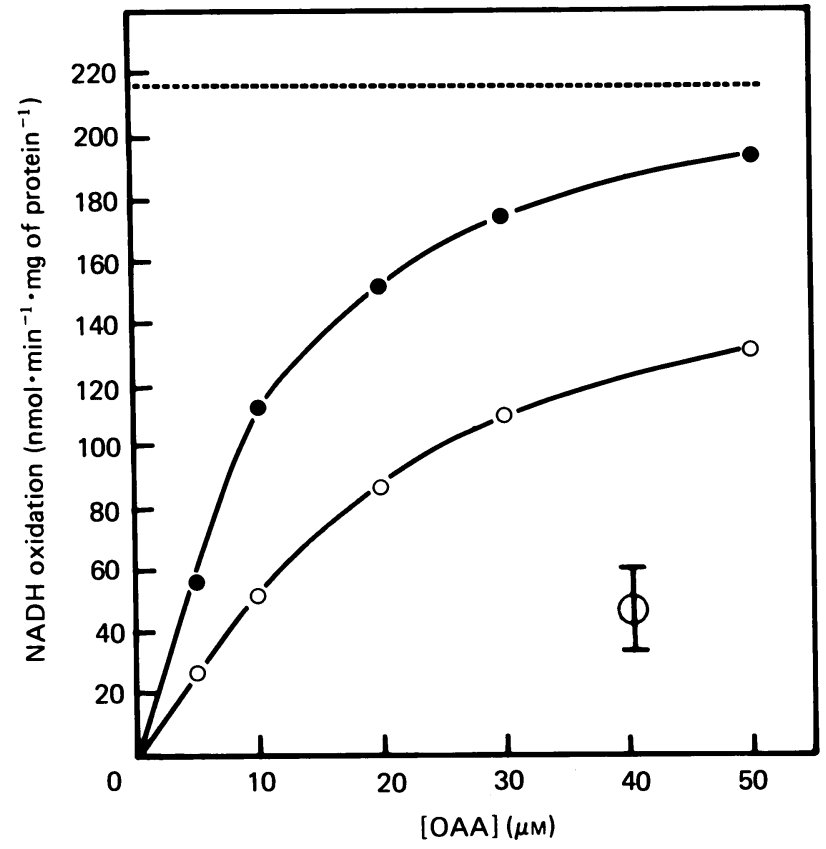

Fig. 5. Comparison of malate/aspartate and malate/oxaloacetate-shuttle activities in purified pea leaf mitochondria

Assays were performed as described in the Experimental section. Symbols: -----, respiratory-chain activity, i.e. rate of glycine-dependent $\mathrm{O}_{2}$ uptake in the presence of $10 \mathrm{~mm}$-glycine and $1 \mathrm{~mm}$-ADP; , degree of inhibition of glycine-dependent $\mathrm{O}_{2}$ uptake by OAA addition; $\mathrm{O}$, malate/OAA-shuttle activity measured via malate efflux; $\Phi$, range of malate/aspartate-shuttle activities measured via malate efflux. All rates have been converted into the effective rate of intramitochondrial NADH oxidation. Results are means for three separate experiments.

\section{Comparison of malate/aspartate- and malate/oxaloacetate-shuttle activities}

The activity of the malate/OAA shuttle can also be estimated from extramitochondrial NADP reduction, as shown in Fig. 4(d). Rates of malate efflux from isolated pea leaf mitochondria were measured over a range of OAA concentrations (Fig. 5). Fig. 5 shows that the estimates of malate/OAA-shuttle activity, based on malate efflux, were found to be consistently lower than that predicted from OAA-dependent inhibition of glycine-dependent $\mathrm{O}_{2}$ uptake. This suggests that the activity of this shuttle may be limited not by OAA uptake but by malate efflux. Even so, the potential reoxidation capacity of the malate/OAA shuttle is greater than the malate/aspartate shuttle at OAA concentrations above 10-15 $\mu \mathrm{M}$. Finally, it should be noted that, over the range of concentrations tested, the reoxidation capacity of both the malate/aspartate and malate/OAA shuttles were significantly lower than that of the mitochondrial respiratory chain under State-3 conditions (Fig. 5).

\section{DISCUSSION}

The results presented indicate that previous estimates of malate/aspartate-shuttle activity across leaf mitochondrial membranes may have been significantly overestimated through the contribution of external AsAT to the generation of OAA. Although the estimated levels of external AsAT are much lower than the intramitochondrial activity (Table 1), the contribution of the external enzyme to the total inhibition of glycine-dependent $\mathrm{O}_{2}$ uptake in the presence of aspartate and 2-OG was found to be equal to that of the matrix enzyme. Clearly, OAA uptake at low concentrations via the high-affinity OAA translocator (Oliver \& Walker, 1984; Ebbighausen et al., 1985) can match the uptake of aspartate and/or 2-OG at high concentrations.

Proudlove \& Moore (1984) have also previously observed a partial reversal of aspartate/2-OG-dependent inhibition of $\mathrm{O}_{2}$ uptake by PTA. However, the concentrations of PTA used in their experiments, i.e. $2.5 \mathrm{~mm}$, did not allow them to resolve whether the reversal was due to an inhibition of 2-OG uptake (see Fig. 2) or an inhibition of uptake of OAA generated by external AsAT. Our data clearly show that the much lower PTA concentrations used in our experiments (Fig. 1) would have been sufficient to inhibit OAA uptake, but have no effect on the rate of 2-OG uptake.

The results of Fig. 3 demonstrate that the estimation of enzyme activities associated with the mitochondrial fraction, but located external to the inner membrane, can be complicated by the presence of that enzyme within the matrix compartment also. This is particularly the case if the substrates and products of this reaction are permeable to the inner membrane. Under such circumstances, steps must be taken to minimize the potential contribution of the matrix enzyme to the estimation of external activity, e.g. use of transport inhibitors such as PTA. However, this may not always be feasible, and alternative methods of enzyme localization must be utilized, e.g. proteinase-hydrolysis profiles (see Soole et al., 1987).

Given that malate efflux represents a valid indicator of shuttle activity, the results of Fig. 5 represent the first published comparison of malate/aspartate and malate/ OAA activities on the same mitochondrial preparations. There is no doubt that the potential capacity of the malate/OAA shuttle exceeds that of the malate/aspartate shuttle. However, if one assumes that cytosolic concentrations of OAA are only of the order of $10 \mu \mathrm{M}$ (Ebbighausen et al., 1985), it can be seen that the potential rates of operation of both shuttles in vivo is in fact very similar. Furthermore, it should be noted that the potential reoxidative capacity of both shuttles under these conditions is still well below that of the mitochondrial respiratory chain under State-3 conditions (Fig. 5).

In order to determine the potential role of these shuttles in the reoxidation of NADH generated during glycine oxidation in vivo, it is necessary to extrapolate these shuttle activities measured with isolated mitochondria to the whole tissue. Tissue rates of glycine decarboxylase activity, based on mitochondrial oxidation rates corrected for breakage during isolation, yield rates ranging from 25 to $46 \mu \mathrm{mol}$ of $\mathrm{CO}_{2}$ evolved $\cdot \mathrm{h}^{-1} \cdot \mathrm{mg}$ of chlorophyll ${ }^{-1}$ (Woo \& Osmond, 1976; Rathnam, 1979; Day \& Wiskich, 1981; Dry, 1984). Malate/aspartateshuttle activities, based on malate efflux, were estimated to be $23 \pm 4 \%(n=5)$ of the State- 3 rate of glycine oxidation, which in turn represents a whole-tissue rate of $5.7-10.6 \mu \mathrm{mol}$ of $\mathrm{CO}_{2}(\mathrm{NADH}) \cdot \mathrm{h}^{-1} \cdot \mathrm{mg}$ of chlorophyll ${ }^{-1}$. [N.B. Malate/aspartate-shuttle activity based on the PTA-insensitive, aspartate/2-OG-dependent, inhibition of $\mathrm{O}_{2}$ uptake by both washed and purified 
pea leaf mitochondria preparations was only marginally higher at $26 \pm 2 \%(n=26)$ of the State- 3 glycine rate.] Virtually identical rates of malate efflux were estimated for the malate/OAA shuttle at $10 \mu \mathrm{M}$-OAA (see Fig. 5), which is well below the estimate of $32 \mu \mathrm{mol}$ of $\mathrm{NADH} \cdot \mathrm{h}^{-1} \cdot \mathrm{mg}$ of chlorophyll ${ }^{-1}$ obtained from OAA uptake measurements (Ebbighausen et al., 1985). This is not surprising, however, when one considers the marked difference in the rates of NADH reoxidation observed between the malate/OAA shuttle and the OAA inhibition of $\Theta_{2}$ uptake (Fig. 5) and raises the question of which of these methods, namely OAA uptake, OAA inhibition of $\mathrm{O}_{2}$ uptake or malate efflux, is the most valid estimate of malate/OAA-shuttle activity.

Current estimates of photorespiratory flux in whole leaf tissue are in the range $25-35 \%$ of the net rate of $\mathrm{CO}_{2}$ fixation (Dry et al., 1987). Thus, assuming an average net photosynthetic rate of $150 \mu \mathrm{mol}$ of $\mathrm{CO}_{2} \cdot \mathrm{h}^{-1} \cdot \mathrm{mg}$ of chlorophyll ${ }^{-1}$, this gives a range of photorespiratory flux through the glycine decarboxylase step of $38-52 \mu \mathrm{mol}$ of $\mathrm{CO}_{2}$ (NADH) $\cdot \mathrm{h}^{-1} \cdot \mathrm{mg}$ of chlorophyll ${ }^{-1}$. A comparison of shuttle activities (above) with the predicted photorespiratory flux in vivo reveals that the capacity of the malate/aspartate shuttle (and, in fact, the malate/ OAA shuttle) is well below that required to support the complete reoxidation and transport of NADH from the mitochondrion to the peroxisome during glycine oxidation.

Schmitt \& Edwards (1983) have previously raised doubts regarding the effective operation of a malate/ aspartate shuttle in leaf tissue, in view of the low levels of peroxisomal AsAT. We conclude, therefore, that the malate/aspartate shuttle is unlikely to play a major role in the reoxidation and export of NADH from leaf mitochondria during photorespiratory glycine oxidation. We also note that, on the basis of the data presented here, there may be serious doubts as to the capacity of a malate/OAA shuttle to mediate on its own the total reoxidation of NADH produced during glycine oxidation in vivo. Consequently, a significant amount of respiratorychain activity would also be required in the light to ensure the complete reoxidation of this NADH. A further ramification of these findings is that an alternative source of reducing power, i.e. the chloroplast (see Ebbighausen et al., 1985), would be required to provide the major portion of the NADH required for hydroxypyruvate reduction within the peroxisome.

Financial support of the Australian Research Grants Scheme is gratefully acknowledged.

\section{REFERENCES}

Arnon, D. I. (1949) Plant Physiol. 24, 1-5

Bergman, A., Ericson, I. (1983) Physiol. Plant. 59, 421-427
Canvin, D. T., Berry, J. A., Badger, M. R., Fock, H. \& Osmond, C. B. (1980) Plant Physiol. 66, 302-307

Chevallier, D. \& Douce, R. (1976) Plant Physiol. 57, 400-402

Day, D. A. (1980) Plant Physiol. 65, 675-679

Day, D. A. \& Wiskich, J. T. (1981) Plant Physiol. 68, 425-429

Day, D. A., Neuburger, M. \& Douce, R. (1985) Aust. J. Plant Physiol. 12, 219-228

Douce, R., Moore, A. L. \& Neuburger, M. (1977) Plant Physiol. 60, 625-628

Dry, I. B. (1984) Ph.D. Thesis, University of Adelaide

Dry, I. B. \& Wiskich, J. T. (1987) Proceedings of the Second International Meeting on Plant Mitochondria, Aberystwyth, July 1986 (Beechey, B. \& Moore, A. L., eds), Plenum Press, in the press

Dry, I. B., Day, D. A. \& Wiskich, J. T. (1983) FEBS Lett. 158, 154-158

Dry, I. B., Bryce, J. H. \& Wiskich, J. T. (1987) in The Biochemistry of Plants: A Comprehensive Treatise (Davies, D. D., ed.), vol. 9, Academic Press, London and New York, in the press

Ebbighausen, H., Chen Jia \& Heldt, H. W. (1985) Biochim. Biophys. Acta 810, 184-199

Fieser, L. F. \& Fieser, M. (1967) Reagents for Organic Synthesis, vol. 1, p. 944, John Wiley and Sons, New York

Gardestrom, P. \& Edwards, G. E. (1985) Encycl. Plant Physiol. New Ser. 18, 314-346

Gardner, J. H. \& Naylor, C. A. (1943) Org. Synth. 2 (collect. vol.), 523-525

Graham, D. (1980) in The Biochemistry of Plants: A Comprehensive Treatise (Davies, D. D., ed.), vol. 2, pp. 526-579, Academic Press, London and New York

Journet, E. P., Neuburger, M. \& Douce, R. (1981) Plant Physiol. 67, 467-469

Kuroda, C. \& Perkin, W. H., Jr. (1923) J. Chem. Soc. 123, 2094-2111

Lowry, O. H., Rosebrough, N. J., Farr, A. L. \& Randall, R. J. (1951) J. Biol. Chem. 193, 265-275

Meijer, A. J., Van Woerkom, G. M. \& Eggelte, T. A. (1976) Biochim. Biophys. Acta 430, 53-61

Moore, A. L., Jackson, C., Halliwell, B., Dench, J. E. \& Hall, D. O. (1977) Biochem. Biophys. Res. Commun. 78, 483-491

Moore, A. L., Jackson, C., Dench, J., Morris, P. \& Hall, D. O. (1979) Plant Physiol. 63, S-110

Nash, D. \& Wiskich, J. T. (1982) Aust. J. Plant Physiol. 9, 715-723

Nash, D. \& Wiskich, J. T. (1983) Plant Physiol. 71, 627-634

Oliver, D. J. \& Walker, G. H. (1984) Plant Physiol. 76, 409-413

Proudlove, M. O. \& Moore, A. L. (1984) Planta 160, 407-414

Rathnam, C. K. M. (1979) Planta 145, 13-23

Schmitt, M. R. \& Edwards, G. E. (1983) Plant Physiol. 72, 728-734

Soole, K. L., Dry, I. B. \& Wiskich, J. T. (1987) Proceedings of the Second International Meeting on Plant Mitochondria, Aberystwyth, July 1986 (Beechey, B. \& Moore, A. L., eds.), Plenum Press, in the press

von Braun, J. (1923) Ber. Dtsch. Chem. Ges. 56, 2332-2343

Wegschieder, R. \& Glogau, A. (1903) Monatsch. Chem. 24, 915-958

Woo, K. C. \& Osmond, C. B. (1976) Aust. J. Plant Physiol. 3, 771-785 